\title{
Luminescence spectroscopy of matrix-isolated atomic cadmium
}

\author{
Brendan Healy \\ Department of Chemistry, National University of Ireland, Maynooth, County Kildare, Ireland \\ John G. McCaffrey ${ }^{\mathrm{a})}$ \\ Department of Chemistry, University of Utah, Salt Lake City, Utah 84112
}

(Received 5 October 1998; accepted 29 October 1998)

\begin{abstract}
The luminescence spectroscopy of atomic cadmium isolated in the solid rare gases is recorded using pulsed synchrotron radiation excitation of the $5 p{ }^{1} P_{1} \leftarrow 5 s{ }^{1} S_{0}$ resonance transition. Steady-state and time-resolved analysis of the ultraviolet (UV) emission bands recorded in the $\mathrm{Cd} / \mathrm{Ne}, \mathrm{Cd} / \mathrm{Ar}$, and Cd/Kr systems allows identification of the associated 227.3, 233.4, and the 241/262 nm bands to the singlet fluorescence of atomic cadmium. The origin of the pair of singlet emission bands at 241 and $262 \mathrm{~nm}$ in the $\mathrm{Cd} / \mathrm{Kr}$ system is ascribed to the coexistence of two nondegenerate minima on the $5 p^{1} T_{1 u}$ surface. The weak band present in the $\mathrm{Cd} / \mathrm{Kr}$ system at $326 \mathrm{~nm}$ and the intense pair at 324.4 and $329.6 \mathrm{~nm}$ in $\mathrm{Cd} / \mathrm{Xe}$ all have decay times longer than $1 \mu$ s and are associated with the triplet transitions of atomic cadmium. Line shape analysis of the near-UV emission pair in $\mathrm{Cd} / \mathrm{Xe}$ allows a tentative assignment of the narrow $329.6 \mathrm{~nm}$ band to the $5 p{ }^{3} P_{0} \rightarrow 5 s{ }^{1} S_{0}$ transition. The intensity of the triplet state emission was observed to be enhanced in the heavier rare gases, being completely absent in $\mathrm{Ne}$ and $\mathrm{Ar}$, weak in $\mathrm{Kr}$, and the only emission observed in Xe. The efficiency of intersystem crossing in the $\mathrm{Cd} / \mathrm{RG}$ systems is very similar to that exhibited by the $\mathrm{Zn} / \mathrm{RG}$ matrix systems. However, the presence of the $5 p^{3} P_{0} \rightarrow 5 s{ }^{1} S_{0}$ emission in $\mathrm{Cd} / \mathrm{Xe}$ resembles the $\mathrm{Hg} / \mathrm{RG}$ matrix systems, a reflection of the larger spin-orbit splitting in atomic cadmium compared with zinc. (C) 1999 American Institute of Physics. [S0021-9606(99)02105-4]
\end{abstract}

\section{INTRODUCTION}

In the recent past, luminescence spectroscopy of matrixisolated metal atoms with $\mathrm{ns}^{2}$ ground electronic configurations has led to considerable insights into the behavior of ground and excited state atoms in condensed matter. In particular, studies on $\mathrm{Mg},{ }^{1} \mathrm{Zn}^{2}$ and $\mathrm{Hg}^{3}$ isolated in the solid rare gases have been very productive, as the matrix results could be compared with the behavior of the corresponding diatomic M.RG van der Waals complexes ${ }^{4}$ stabilized in cold supersonic expansions. Of the Group 12 (IIB) metal atom $\mathrm{ns}^{2}$ systems, the absence of luminescence data on the $\mathrm{Cd} / \mathrm{RG}$ matrix series is particularly acute because (1) cadmium provides a link between the behavior of the lighter elements in the series ( $\mathrm{Mg}$ and $\mathrm{Zn}$ ) with the heaviest metal $\mathrm{Hg}$, and (2) accurate experimental pair potentials, ${ }^{5,6}$ already exist for the Cd·RG 1:1 complexes.

Absorption spectra of matrix-isolated atomic cadmium have been recorded by several workers. ${ }^{7}$ In the most recent work, Laursen and Cartland ${ }^{8}$ recorded transmittance spectra indicating threefold splittings on the singlet $5 s^{1} 5 p^{1}{ }^{1} P_{1}$ $\leftarrow 5 s^{2}{ }^{1} S_{0}$ Cd transition characteristic of Jahn-Teller interaction in the excited $5 s^{1} 5 p^{11} P_{1}$ state. Of the rare gases $\mathrm{Ar}$, $\mathrm{Kr}$, and Xe used as hosts in the study of Laursen and Cartland, a redshift from the position of the gas phase transition ${ }^{9}$ was only observed in Xe. Arguments based on the polarizabilities of the rare gases $\mathrm{Ar}, \mathrm{Kr}$, and $\mathrm{Xe}$ were presented

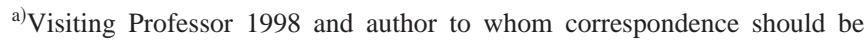
addressed. Permanent address: Department of Chemistry, National University of Ireland, Maynooth, County Kildare, Ireland. which accounted for the trends observed in the matrix shifts but which could not account for the occurrence of the blue shifts in $\mathrm{Ar}$ and $\mathrm{Kr}$ systems when it is known from gas phase work $^{5,6}$ that the excited $\mathrm{Cd}\left(5 p{ }^{1} P_{1}\right) \cdot \mathrm{RG}^{1} \Pi_{1}$ states are more deeply bound than the ground $\operatorname{Cd}\left(5 s^{1} S_{0}\right) \cdot \mathrm{RG}^{1} \Sigma_{1}$ states.

As mentioned above, the van der Waals radii of atomic Cd interacting with rare gas atoms are known from the spectroscopic analysis of Breckenridge and co-workers ${ }^{5,6}$ on 1:1 $\mathrm{Cd} \cdot \mathrm{RG}$ complexes. Rotationally resolved data recorded ${ }^{5}$ on $\mathrm{Cd} \cdot \mathrm{Ne}$ and $\mathrm{Cd} \cdot \mathrm{Ar}$ indicated equilibrium internuclear separations of 4.26 and $4.31 \AA$, respectively, for the ground $X^{1} \Sigma_{0}^{+}$ state potentials of these diatomics. Due to isotopic congestion and very efficient spin-orbit predissociation in the $C^{1} \Pi$ states of the $\mathrm{Cd} \cdot \mathrm{Kr}$ and $\mathrm{Cd} \cdot \mathrm{Xe}$ complexes, respectively, rotational analysis of the $C^{1} \Pi \leftarrow X^{1} \Sigma_{0}^{+}$excitation spectra was not possible for these heavier rare gas complexes. However, reliable estimates of 4.33 and $4.55 \AA$ were presented ${ }^{6}$ for the ground state bond lengths of $\mathrm{Cd} \cdot \mathrm{Kr}$ and $\mathrm{Cd} \cdot \mathrm{Xe}$, respectively. With this information on the bond lengths of the Cd.RG diatomics and knowledge of the substitutional site diameters of the solid rare gases, (3.09, 3.76, 4.01, and $4.35 \AA$ for Ne, $\mathrm{Ar}, \mathrm{Kr}$, and Xe, respectively ${ }^{10}$ ) it can be stated with confidence that atomic cadmium will occupy a single substitutional site in $\mathrm{Kr}$ and $\mathrm{Xe}$ but will not fit in such a site of Ne. Identification of the site occupancy in Ar requires calculation.

In the present contribution, the luminescence spectroscopy of matrix-isolated atomic cadmium is presented in steady-state and time-resolved measurements. Comparisons between the behavior observed in previous matrix lumines- 


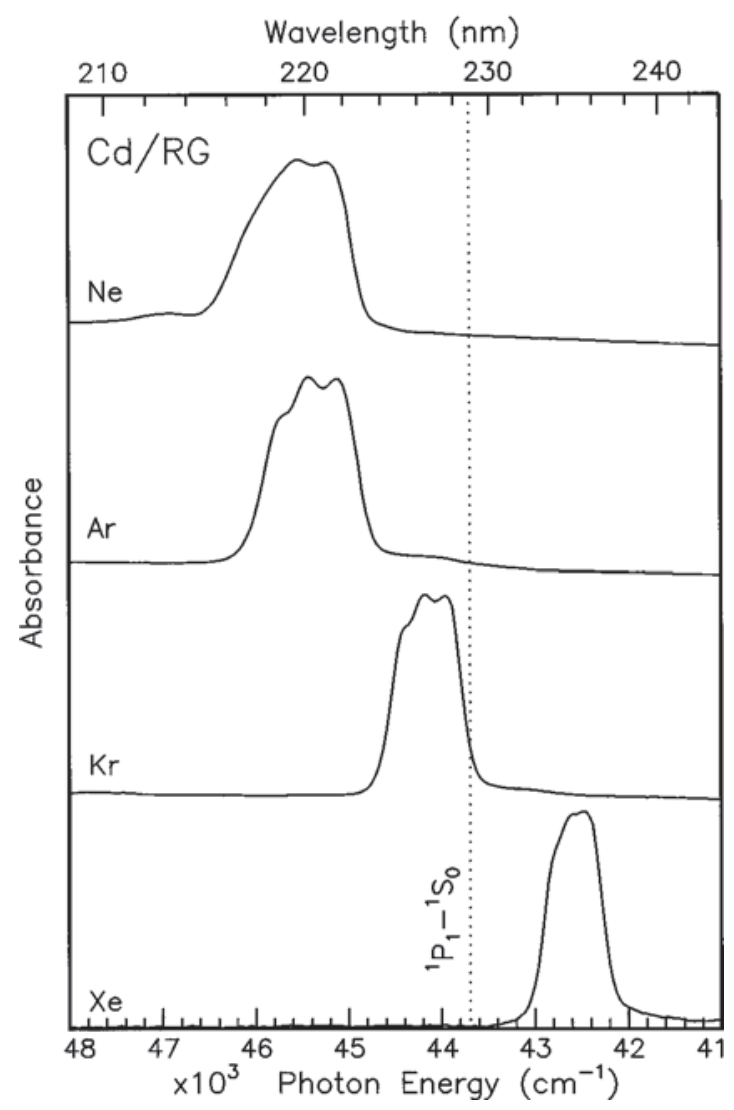

FIG. 1. Absorption spectra recorded at $4.5 \mathrm{~K}$ for atomic cadmium isolated in the solid rare gases. The $\mathrm{Cd} / \mathrm{RG}$ samples were formed by codeposition of $\mathrm{Cd}$ vapor with the rare gases on a $\mathrm{LiF}$ window at temperatures of 5, 12, 20, and $25 \mathrm{~K}$ for $\mathrm{RG}=\mathrm{Ne}$, Ar, Kr, and Xe, respectively. For comparison, the position of the $5 p{ }^{1} P_{1}-5 s{ }^{1} S_{0}$ transition of gas phase atomic cadmium is also shown.

cence studies of the lighter $\mathrm{Zn}$ and heavier $\mathrm{Hg}$ metal atoms of this group with the present study will also be made. A preliminary analysis of the temperature dependence exhibited by the pair of singlet emission bands in the $\mathrm{Cd} / \mathrm{Kr}$ system is included.

\section{EXPERIMENT}

Solid Cd/RG samples were prepared by the cocondensation of cadmium vapor, produced by electron bombardment of $0.5 \mathrm{~mm}$ cadmium foil, Goodfellow 99.99\% purity, coiled into a $5 \mathrm{~mm}$ diameter molybdenum crucible in an Omicron EFM3 ultrahigh vacuum (UHV) evaporator, with the rare gases $\mathrm{Ne}, \mathrm{Ar}, \mathrm{Kr}$, and $\mathrm{Xe}$ onto an $\mathrm{LiF}$ window at 5, 12, 18, and $25 \mathrm{~K}$, respectively. The preferential isolation of atoms over metal clusters was achieved by using very low metal fluxes $(<1 \mathrm{nA})$, and the isolation conditions of all samples were monitored by recording their absorption spectra. The absorption spectra of the $\mathrm{Cd} / \mathrm{RG}$ samples used in the present luminescence study are presented in Fig. 1. An MKS 221A Baratron capacitance manometer, sensitive in the pressure range 0-1000 mbar, was employed to monitor the amounts of rare gas admitted to the gas handling system and consumed during sample formation. The UHV sample chamber was pumped continuously with a Pfeiffer/Balzers TPU 240 turbomolecular pump. Prior to, but not during deposition, a
CTI Cryogenics “'Cryo-Torr” high vacuum pump was used to improve the vacuum still further. The vacuum was monitored with an HPS Division/MKS Series 423 I-Mag cold cathode ionization gauge-values in the mid $10^{-10} \mathrm{mbar}$ range were achieved prior to cool-down, dropping to $10^{-11}$ mbar after cool-down. Gas flow rates were controlled by a Granville-Phillips series 203 variable leak valve and were generally in the range of 3.5 to $5 \mathrm{mmol} / \mathrm{hr}$ for periods of between 20 and 30 min. Rare gases of $99.999 \%$ purity were used as supplied by Linde Technische Gase.

Synchrotron radiation optimized in the VUV spectral region was used as the excitation source. Since the optical layout of the HIGITI apparatus located at HASYLAB/DESY in Hamburg has been shown in earlier work, ${ }^{2}$ only a brief description will be presented here, emphasizing any alterations made to the setup previously used. Absorption spectra were recorded, by monitoring the amount of UV radiation directly transmitted through the $\mathrm{Cd} / \mathrm{RG}$ samples using a Valvo XP2020Q photomultiplier tube to detect the visible emission of a sodium salicylate UV to visible converter. Absorption spectra of the Cd/RG samples were obtained by ratioing with the corresponding RG blanks. All spectra were recorded linear in wavelength, but for the purposes of analysis and discussion are presented linear in energy in wave number $\left(\mathrm{cm}^{-1}\right)$ units.

Steady-state luminescence (emission and excitation) measurements were made with a secondary monochromator, either a $0.4 \mathrm{~m}$ Seya-Namioka monochromator for the VUV/ near-UV regions, or a $0.25 \mathrm{~m}$ Spex $240 \mathrm{M}$ monochromator for the UV-visible region. A Hamamatsu MCP 1645U-09 microchannel plate was used for photon detection on the Seya-Namioka, while a CCD-array, Tektronix SITe-type detector, cooled to $-100^{\circ} \mathrm{C}$, was used on the Spex monochromator. Sample annealing was achieved with a heater mounted on the cold tip of the liquid helium cryostat. Temperatures were measured with a silicon diode mounted on the sample holder and set using a Lakeshore Cryotronics, model 330, temperature controller.

Nanosecond lifetime measurements were made using the time correlated single photon counting (TCSPC) technique. ${ }^{11}$ The synchrotron radiation ${ }^{12}$ (SR) generated from the DORIS III storage ring at HASYLAB/DESY has a temporal profile whose full width at half maximum (FWHM) is 120 ps, and when provided in the " 5 Bunch Mode" at a repetition rate of $5.208 \mathrm{MHz}$, decay times of up to $1 \mu$ s can be measured with the TCSPC technique. Decay times were extracted by fitting trial functions, either single or double exponential functions, convoluted with the temporal profile of the SR excitation pulse, to the recorded decay profiles. The reconvolution and fitting were achieved using the "ZFIT"' program ${ }^{13}$ running on DEC Alpha 3000/500 AXP workstations in Maynooth and Hamburg. The fitting criterion was based on an optimization routine minimizing the sum of weighted residuals existing between the fit and the data set. ${ }^{11}$ The quality of a fit can be judged numerically by the $\chi^{2}$ value obtained-in our fits the acceptable range was 0.98 to 1.10 . 


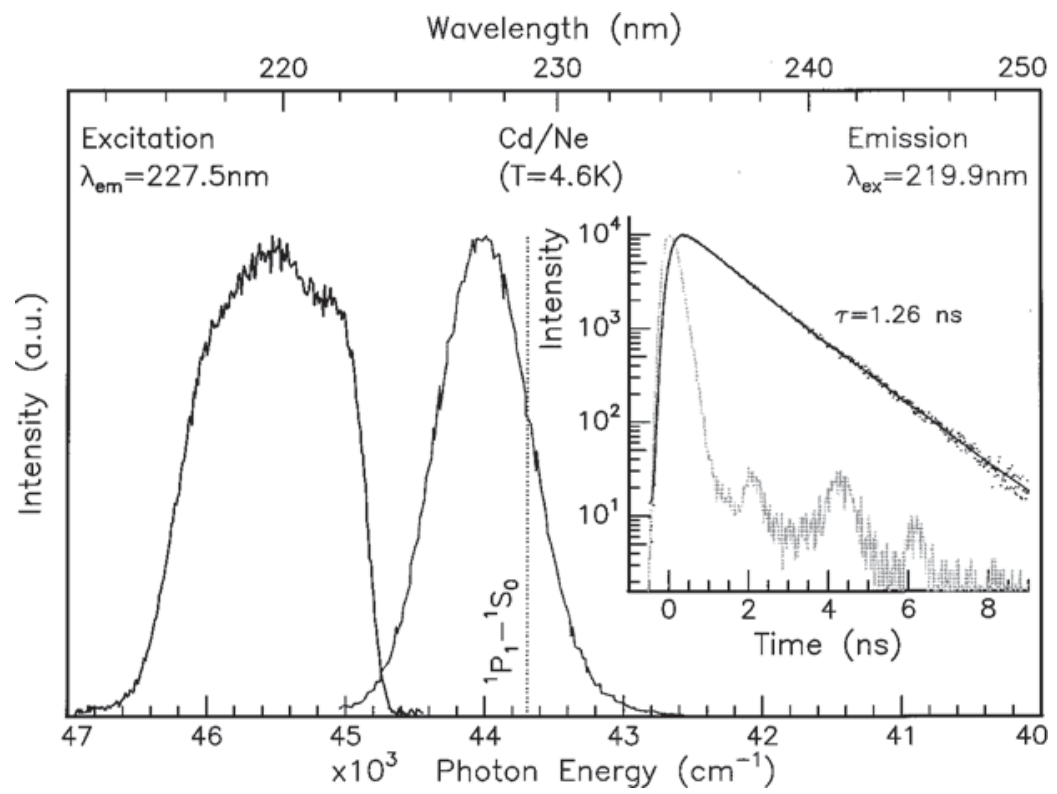

FIG. 2. Emission and excitation spectra recorded for a $\mathrm{Cd} / \mathrm{Ne}$ sample at $4.6 \mathrm{~K}$. The location of the $\mathrm{Cd} 5 p{ }^{1} P_{1}$ $-5 s{ }^{1} S_{0}$ transition in the gas phase is also shown. The inset shows a semilog plot of the $227 \mathrm{~nm}$ emission decay curve (dots) recorded with the TCSPC technique and produced with excitation at $219 \mathrm{~nm}$. The temporal profile of the synchrotron excitation pulse is shown centered at $t=0$ as the grey trace. A fit of the emission decay curve with a single exponential function having $\tau=1.26 \mathrm{~ns}$ is shown by the solid line.

\section{RESULTS}

\section{A. $\mathrm{Cd} / \mathrm{Ne}$}

An excitation wavelength of $219.9 \mathrm{~nm}$, chosen from the $\mathrm{Cd} / \mathrm{Ne}$ absorption spectrum shown in Fig. 1, produced the emission band centered at $227 \mathrm{~nm}$ shown in the center of Fig. 2. Although not shown in Fig. 2, scans out to $500 \mathrm{~nm}$ revealed the existence of no other emission bands. Thus the $\mathrm{Cd} / \mathrm{Ne}$ system does not exhibit triplet emission expected in the 320-330 $\mathrm{nm}$ region. The excitation profile recorded by monitoring the $227.5 \mathrm{~nm}$ emission band is shown on the left in Fig. 2. It exhibits the threefold splitting present on the absorption band, and with a bandwidth of $1338 \mathrm{~cm}^{-1}$, is considerably broader than the emission band, whose FWHM is listed in Table I as $812 \mathrm{~cm}^{-1}$. The lack of mirror symmetry in the excitation and emission profiles is clearly evident in Fig. 2, as the former exhibits threefold splitting while the

TABLE I. Photophysical characteristics of the singlet $5 p{ }^{1} P_{1}-5 s{ }^{1} S_{0}$ transition of matrix-isolated atomic cadmium at $4.5 \mathrm{~K}$. The excitation wavelength indicated $\lambda_{\text {ex }}$ is the central component in the threefold split absorption band. $\Delta$ is the full width at half maximum intensity of the excitation/ emission features, while SS is the Stokes shift, both of which are quoted in wave number $\mathrm{cm}^{-1}$ units. $\tau$ is the radiative lifetime.

\begin{tabular}{|c|c|c|c|c|c|c|}
\hline \multirow[b]{2}{*}{ System } & \multicolumn{2}{|c|}{ Excitation } & \multicolumn{4}{|c|}{ Emission } \\
\hline & $\lambda_{\mathrm{ex}}(\mathrm{nm})$ & $\Delta\left(\mathrm{cm}^{-1}\right)$ & $\lambda_{\mathrm{em}}(\mathrm{nm})$ & $\Delta\left(\mathrm{cm}^{-1}\right)$ & $\tau(\mathrm{ns})$ & $\mathrm{SS}\left(\mathrm{cm}^{-1}\right)$ \\
\hline Gas Phase $^{\mathrm{a}}$ & 228.87 & $\cdots$ & 228.87 & $\cdots$ & $1.89^{\mathrm{b}}$ & $\cdots$ \\
\hline $\mathrm{Ne}$ & $\left\{\begin{array}{l}217.5 \\
219.5 \\
221.5\end{array}\right.$ & 1338 & 227.3 & 812 & 1.26 & 1567 \\
\hline $\mathrm{Ar}$ & $\left\{\begin{array}{l}218.8 \\
220.4 \\
222.2\end{array}\right.$ & 1157 & 233.4 & 878 & 1.07 & 2519 \\
\hline $\mathrm{Kr}$ & $\left\{\begin{array}{l}225.5 \\
226.3 \\
227.9\end{array}\right.$ & 855 & $\begin{array}{c}241.3 \\
262.0\end{array}$ & $\begin{array}{l}1034 \\
1350\end{array}$ & $\begin{array}{l}1.01 \\
1.62\end{array}$ & $\begin{array}{l}2742 \\
6021\end{array}$ \\
\hline
\end{tabular}

${ }^{a}$ Data from Reference 9.

bata from Reference 14 emission band is featureless. It can also be seen in Fig. 2 that both the excitation and the emission are blue shifted compared to the gas phase $5 s^{1} 5 p^{1}{ }^{1} P_{1} \leftarrow 5 s^{2}{ }^{1} S_{0}$ transition. Annealing to $8.5 \mathrm{~K}$ had no effect on the emission or excitation bands, so for samples made at $5 \mathrm{~K}, \mathrm{Cd} / \mathrm{Ne}$ is free of the trapping of atomic cadmium in multiple sites.

The decay curve recorded for the $227 \mathrm{~nm}$ emission in a 10 ns range with the TCSPC technique is shown inset in Fig. 2 , on a semilog plot. It was fit yielding excellent statistics, $\chi^{2}=1.01$, with a single exponential function having a decay time of 1.26 ns. The fit is shown in Fig. 2 as the solid line through the recorded decay curve, represented by the dots, while the time structure of the synchrotron radiation is shown, centered at $t=0$, by the solid curve. The value of the decay time extracted from the fit, 1.26 ns, was observed to be independent of temperature in the 4-8 $\mathrm{K}$ range accessible in Ne. From the lack of temperature dependence exhibited by the decay time, $1.26 \mathrm{~ns}$ is identified as the radiative lifetime of the $\mathrm{Cd} / \mathrm{Ne} 227 \mathrm{~nm}$ emission. Since the $5 s^{1} 5 p^{1}{ }^{1} P_{1}$ $\rightarrow 5 s^{2}{ }^{1} S_{0}$ transition of atomic cadmium occurs at $228.87 \mathrm{~nm}$ in the gas phase ${ }^{9}$ with a lifetime ${ }^{14}$ of $1.89 \mathrm{~ns}$, the $227 \mathrm{~nm}$, emission in solid neon clearly originates from the excited $5 s^{1} 5 p^{11} P_{1}$ state of atomic Cd.

\section{B. $\mathrm{Cd} / \mathrm{Ar}$}

The emission spectrum recorded at $5 \mathrm{~K}$ using $220.2 \mathrm{~nm}$ excitation of an annealed $\mathrm{Cd} / \mathrm{Ar}$ sample is shown by the uppermost trace on the right in Fig. 3. Two emission bands are observed; a dominant band centered at $233.5 \mathrm{~nm}$ and a weak shoulder centered at $244 \mathrm{~nm}$. The excitation band exhibiting threefold splitting was recorded by monitoring the dominant emission at $233.4 \mathrm{~nm}$. That recorded by monitoring the $247 \mathrm{~nm}$ band in a freshly deposited sample is shown on the bottom left in Fig. 3. The excitation spectrum of the $247 \mathrm{~nm}$ emission is complex, and at $228 \mathrm{~nm}$ overlaps the dominant $233.5 \mathrm{~nm}$ emission. When $228 \mathrm{~nm}$ excitation was 


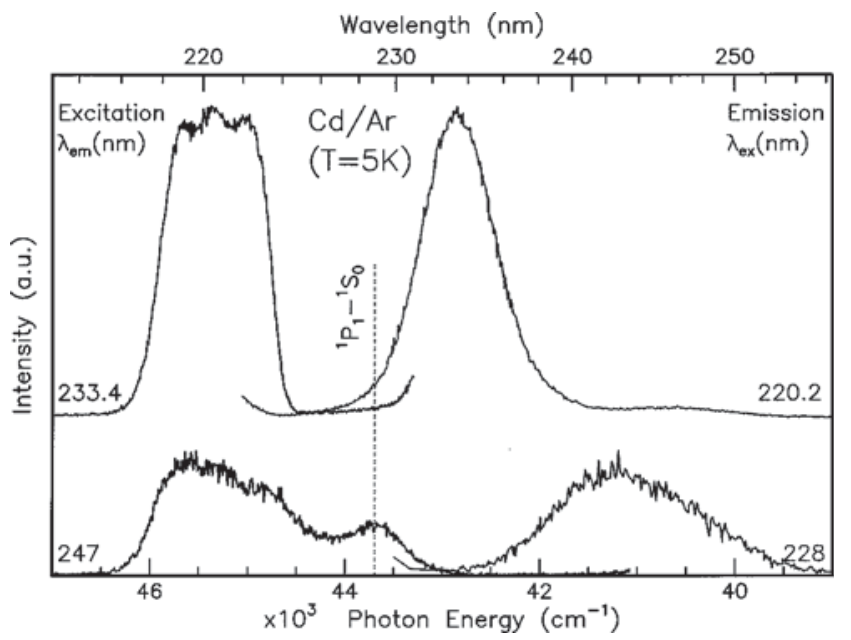

FIG. 3. The top panel shows the emission and excitation spectra recorded at 5.0 K for a $\mathrm{Cd} / \mathrm{Ar}$ sample annealed to $31 \mathrm{~K}$. As in the $\mathrm{Cd} / \mathrm{Ne}$ system, a lack of mirror symmetry in the excitation and emission profiles is exhibited, but in this case the bandwidths are similar. The weak sideband at $245 \mathrm{~nm}$ in the emission spectrum is due to a site whose excitation, shown on the bottom left of the figure, is distinct from that of the dominant $233 \mathrm{~nm}$ emission band. Annealing was found to diminish the intensity of the $245 \mathrm{~nm}$ feature and is thereby assigned to occupancy of atomic Cd in a thermally unstable site.

selected, a broad, weak emission band centered at $244 \mathrm{~nm}$ was recorded alone, as shown by the lower trace on the right of Fig. 3.

Annealing was found to reduce the intensity of the 244 $\mathrm{nm}$ emission. After annealing to $30.5 \mathrm{~K}$ for a period of 20 minutes, the emission band shown on the upper right was recorded. Due to the reduction in the intensity of this feature, a significant increase was observed in the intensity of the 233 $\mathrm{nm}$ emission band after annealing. It is concluded then that the former emission band is associated with the occupancy of atomic cadmium in a thermally unstable site present in the freshly deposited Cd/Ar samples. No change was observed in the emission spectrum recorded at temperatures up to $28 \mathrm{~K}$, other than the anticipated linewidth broadening. The positions of the resolved features in threefold split absorption and excitation spectra in the annealed $\mathrm{Cd} / \mathrm{Ar}$ samples were identical. Their values are listed in Table I as 218.8, 220.4, and $222.2 \mathrm{~nm}$.

In contrast to the $\mathrm{Cd} / \mathrm{Ne}$ system, the gas phase $5 s^{1} 5 p^{11} P_{1} \leftarrow 5 s^{2}{ }^{1} S_{0}$ transition of cadmium is, as shown in the top panel of Fig. 3, located between the excitation and emission bands in the Cd/Ar system. The Stokes shift, calculated from the central component of the threefold split excitation band is $2519 \mathrm{~cm}^{-1}, 1000 \mathrm{~cm}^{-1}$ larger than that observed in the $\mathrm{Cd} / \mathrm{Ne}$ system. Because of the larger Stokes shift in $\mathrm{Cd} / \mathrm{Ar}$, there is no overlap of the excitation and emission bands as was observed in $\mathrm{Cd} / \mathrm{Ne}$. However, as was observed in the $\mathrm{Cd} / \mathrm{Ne}$ system, a lack of mirror symmetry is also exhibited in $\mathrm{Cd} / \mathrm{Ar}$, with threefold splitting on the excitation band and the emission featureless.

Decay curves recorded for the $233 \mathrm{~nm}$ emission before and after annealing were identical. The 1.07 ns decay time extracted from single exponential fits of the recorded decay curves was also found to be independent of temperature in

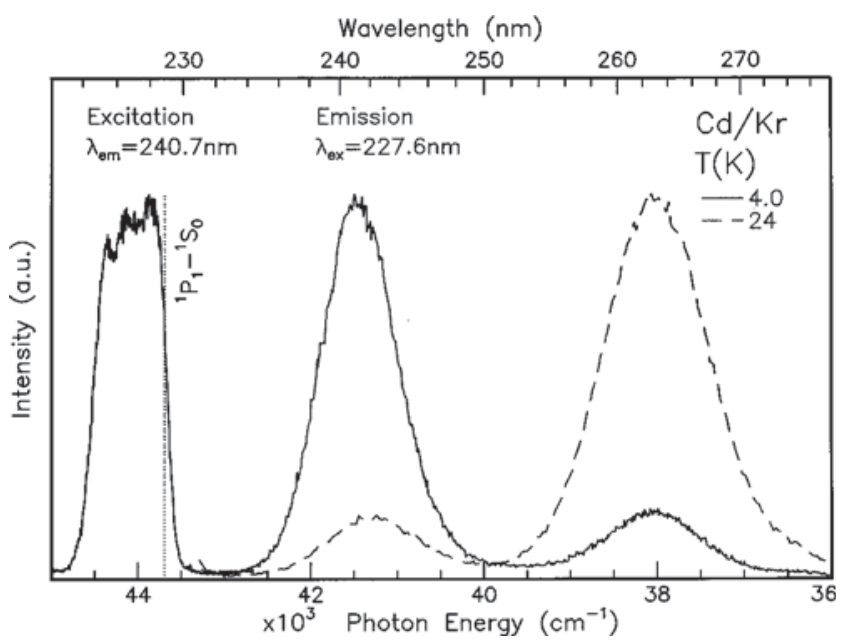

FIG. 4. Emission and excitation spectra recorded at $4.0 \mathrm{~K}$ for a $\mathrm{Cd} / \mathrm{Kr}$ sample. The second, weaker emission feature at $262 \mathrm{~nm}$ is, in contrast to the $\mathrm{Cd} /$ Ar system, not due to an additional site, as its excitation was found to be identical to the dominant emission band at $241.3 \mathrm{~nm}$. With increasing temperature, the intensity of the $262 \mathrm{~nm}$ emission band is favored over the 241.3 nm band, as shown in Fig. 4 by the dashed line for $T=24 \mathrm{~K}$.

the range $4-29 \mathrm{~K}$ and is accordingly identified as the radiative lifetime of the $5 s^{1} 5 p^{11} P_{1}$ state of $\mathrm{Cd}$ in $\mathrm{Ar}$.

\section{C. $\mathrm{Cd} / \mathrm{Kr}$}

The emission spectrum recorded at $4 \mathrm{~K}$ in $\mathrm{Cd} / \mathrm{Kr}$ with $227.6 \mathrm{~nm}$ excitation comprises two emission features in the UV region and a single, weak band at $324 \mathrm{~nm}$ in the near-UV region. As shown on the right in Fig. 4, an intense emission band is located at 241 and a weaker band at $262 \mathrm{~nm}$. The excitation spectra recorded for all three emission bands were identical - that recorded at $4 \mathrm{~K}$ for the $241 \mathrm{~nm}$ band had the best signal-to-noise ratio and is shown on the left in Fig. 4. Annealing had no affect on the emission bands, but as shown in Fig. 4, temperature had a pronounced effect. The dotted line in Fig. 4 shows the emission recorded at $24 \mathrm{~K}$ with $227.6 \mathrm{~nm}$ excitation of a sample that had already been annealed to $40 \mathrm{~K}$. At this temperature the $262 \mathrm{~nm}$ emission dominates, but as the sample temperature is reduced below 8 $\mathrm{K}$, the original low temperature spectrum, shown by the solid line in Fig. 4, is restored. From the observation that both emission bands have identical excitation profiles, one can conclude that multiple site occupancy is not responsible for the $241 / 262 \mathrm{~nm}$ emission pair.

Decay curves recorded for the pair of near-UV emission bands could be fit at low temperatures $(4<T<8 \mathrm{~K})$ with single exponential functions. The decay times of the 241 and $262 \mathrm{~nm}$ bands were 1.01 and $1.62 \mathrm{~ns}$, respectively, and due to their temperature invariance below $8 \mathrm{~K}$, are identified as the radiative lifetimes of these emissions. With radiative lifetimes of these magnitudes, and considering their spectral location, it can be concluded that both the 241 and $262 \mathrm{~nm}$ emission bands originate from the $5 s^{1} 5 p^{1} P_{1} \rightarrow 5 s^{2} S_{0}$ transition of cadmium. The temperature dependence exhibited in the emission spectrum indicates that population in a higher energy level can reach the lower level after surmounting a barrier. The origin of the pair of emitting levels in the 


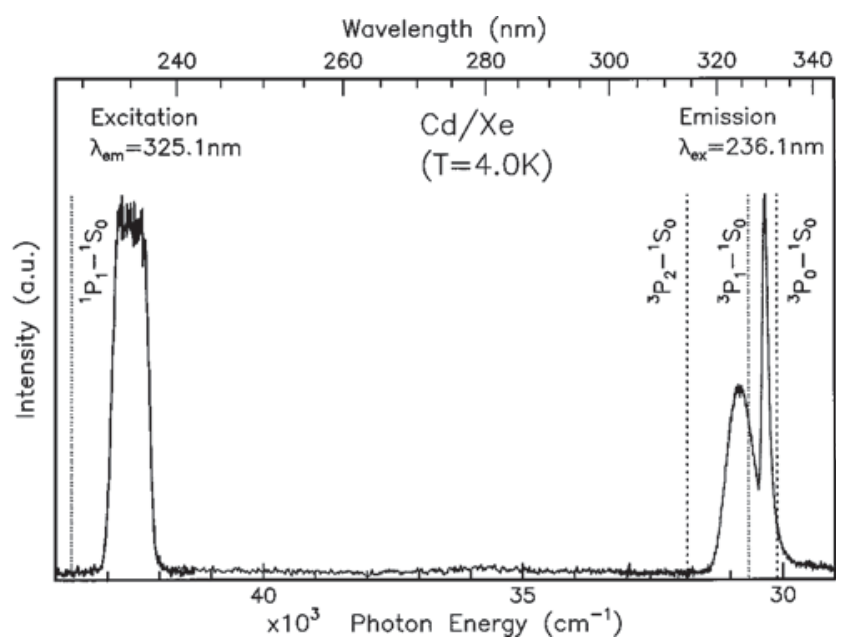

FIG. 5. Emission and excitation spectra recorded at $4.0 \mathrm{~K}$ for a $\mathrm{Cd} / \mathrm{Xe}$ sample. Note the absence of any emission in the vicinity of the singlet 236 $\mathrm{nm}$ absorption band shown in Fig. 1 or the excitation band shown on the left. The pair of emission bands in the 320-330 nm region were recorded with a CCD camera and their locations are compared with those of the $5 p{ }^{3} P_{J}-5 s{ }^{1} S_{0}(J=2,1$ and 0$)$ transitions of gas phase atomic cadmium. The excitation band was recorded by monitoring emission at $324 \mathrm{~nm}$ under low resolution.

$\mathrm{Cd}\left({ }^{1} P_{1}\right) / \mathrm{Kr}$ matrix system will be discussed later. A decay curve of the near-UV emission at $324 \mathrm{~nm}$ could not be recorded using the TCSPC technique as the decay time was much longer than the 192 ns interval between excitation pulses present at a repetition rate of $5.208 \mathrm{MHz}$. On the basis of previous decay time measurements, ${ }^{2}$ it can be stated that the decay time of the $324 \mathrm{~nm}$ emission is longer than $1 \mu \mathrm{s}$. Given that the triplet $5 s^{1} 5 p^{13} P_{J} \rightarrow 5 s^{2}{ }^{1} S_{0}$ transitions of gas phase atomic cadmium occur in this spectral region and the most allowed ${ }^{3} P_{1} \rightarrow{ }^{1} S_{0}$ transition has a lifetime ${ }^{14}$ of 2.46 $\mu \mathrm{s}$, it is concluded that the $325 \mathrm{~nm}$ band in $\mathrm{Kr}$ originates from a spin triplet transition.

\section{D. $\mathrm{Cd} / \mathrm{Xe}$}

Shown on the right in Fig. 5 is the emission spectrum recorded with excitation at $236.1 \mathrm{~nm}$ for atomic cadmium isolated in a xenon matrix deposited at $25 \mathrm{~K}$. Two emission bands with very different linewidths are observed at $4 \mathrm{~K}$ in the near-UV at 324.4 and $329.6 \mathrm{~nm}$. The FWHM of the 324 $\mathrm{nm}$ band is listed in Table II as $643 \mathrm{~cm}^{-1}$, more than four times the $149 \mathrm{~cm}^{-1}$ FWHM of the $329.6 \mathrm{~nm}$ band. In contrast to all the other $\mathrm{Cd} / \mathrm{RG}$ matrix systems, no emission was detectable in the UV region for $\mathrm{Cd} / \mathrm{Xe}$ with singlet $5 s^{1} 5 p^{11} P_{1} \leftarrow 5 s^{2}{ }^{1} S_{0}$ excitation. An excitation spectrum recorded by monitoring the broader emission at $325 \mathrm{~nm}$ is shown on the left in Fig. 5. An identical excitation profile was recorded by monitoring the $329 \mathrm{~nm}$ emission band. Annealing of $\mathrm{Cd} / \mathrm{Xe}$ samples deposited at $25 \mathrm{~K}$ produced no changes in the emission spectra. However, a reversible temperature dependence was observed between the relative intensities of the 324 and $329 \mathrm{~nm}$ emission pair, an effect which will be analyzed and presented later when precise decay times have been measured.
TABLE II. Photophysical characteristics of the triplet $5 p{ }^{3} P_{1}-5 s{ }^{1} S_{0}$ transition of matrix-isolated atomic cadmium at $4.5 \mathrm{~K}$. The excitation wavelength indicated $\lambda_{\mathrm{ex}}$ is the central component in the threefold split singlet absorption band. All other symbols have the same meaning as in Table I.

\begin{tabular}{ccccccc}
\hline \hline & \multicolumn{3}{c}{ Excitation } & \multicolumn{5}{c}{ Emission } \\
\cline { 2 - 7 } System & $\begin{array}{c}\lambda_{\mathrm{ex}} \\
(\mathrm{nm})\end{array}$ & $\begin{array}{c}\Delta \\
\left(\mathrm{cm}^{1}\right)\end{array}$ & $\begin{array}{c}\lambda_{\mathrm{em}} \\
(\mathrm{nm})\end{array}$ & $\begin{array}{c}\Delta \\
\left(\mathrm{cm}^{-1}\right)\end{array}$ & $\tau(\mu \mathrm{s})$ & $\begin{array}{c}\mathrm{SS} \\
\left(\mathrm{cm}^{-1}\right)\end{array}$ \\
\hline Gas Phase $^{\mathrm{a}}$ & 228.87 & $\ldots$ & 326.2 & & 2.46 & $\ldots$ \\
& 225.5 & & 332.07 & & metastable & \\
$\mathrm{Kr}$ & 226.3 & 855 & 326 & 50 & $>1$ & 2810 \\
& 227.9 & & & & & \\
$\mathrm{Xe}$ & 233.8 & & & & & \\
& 235 & 724 & 324.4 & 643 & $>1$ & NA \\
\hline \hline
\end{tabular}

${ }^{\mathrm{a}}$ Data from Reference 9.

${ }^{\mathrm{b}}$ Data from Reference 14.

Decay curves for the 324 and $329 \mathrm{~nm}$ emission bands could not be measured with $5 \mathrm{MHz}$ synchrotron excitation using the TCSPC technique, indicating, as in the near-UV emission band of the $\mathrm{Cd} / \mathrm{Kr}$ system, that the decay times of both bands are longer than $1 \mu \mathrm{s}$.

\section{DISCUSSION}

\section{A. Spectral assignments}

A summary of the excitation and emission spectra recorded in annealed Cd/RG samples is presented in Fig. 6 for the systems $\mathrm{Ne}, \mathrm{Ar}$, and $\mathrm{Kr}$ exhibiting singlet emission, while a summary of the $\mathrm{Cd} / \mathrm{Kr}$ and $\mathrm{Cd} / \mathrm{Xe}$ systems which exhibit triplet emission is presented in Fig. 7. The excitation bands, centered at 219.5, 220.4, 226.3, and $235 \mathrm{~nm}$ in neon, argon, krypton, and xenon, respectively, are identical to the absorption bands shown in Fig. 1. In accordance with previous absorption studies, these bands are identified as the solid

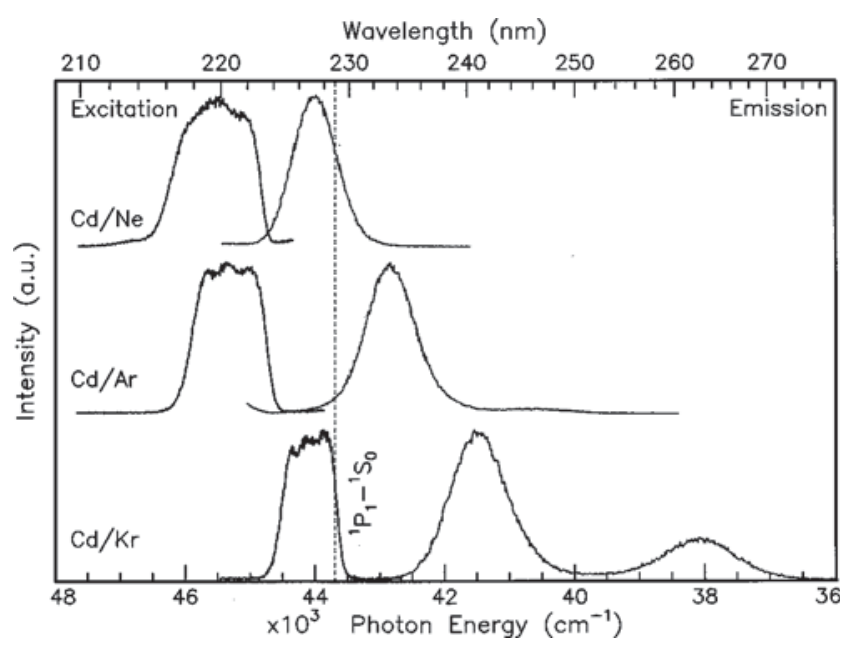

FIG. 6. A summary of the excitation and emission spectra recorded for the spin singlet transitions of Cd isolated in annealed solid rare gas samples. The excitation spectra are shown in black on the left of the figure, while their corresponding emission spectra are shown on the right in grey. The gas phase singlet $5 p{ }^{1} P_{1}-5 s{ }^{1} S_{0}$ resonance transition of atomic cadmium is indicated by the vertical dotted line for comparison. 


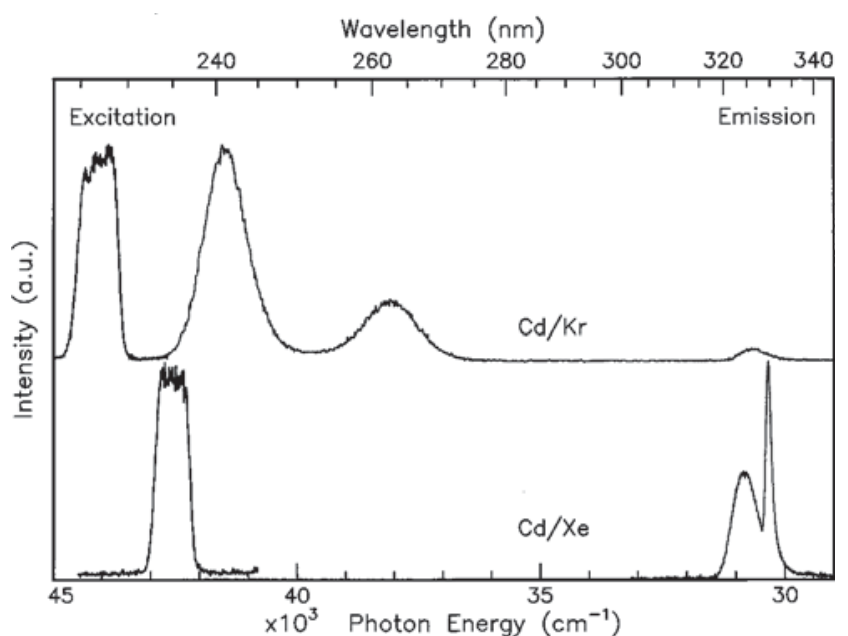

FIG. 7. As in Fig. 6, but for the $\mathrm{Cd} / \mathrm{Kr}$ and $\mathrm{Cd} / \mathrm{Xe}$ systems which exhibit spin triplet emission.

phase equivalent of the $5 p{ }^{1} P_{1} \leftarrow 5 s{ }^{1} S_{0}$ resonance transition of atomic cadmium occurring at $228.87 \mathrm{~nm}$ in the gas phase. ${ }^{9}$ The characteristic threefold splitting evident in the absorption spectra of Fig. 1 for the ${ }^{1} P_{1} \leftarrow{ }^{1} S_{0}$ transition of matrixisolated atomic cadmium is attributed to dynamic JahnTeller coupling ${ }^{15}$ in the excited $5 p^{1} P_{1}$ state. The larger splitting evident in Fig. 1 on the ${ }^{1} P_{1} \leftarrow{ }^{1} S_{0}$ transition in the lighter rare gas hosts is related to the larger absorption bandwidths, $\Delta=1338,1157,855$, and $724 \mathrm{~cm}^{-1}$ listed in Tables I and II for Ne through Xe.

The 227, 233, and $241 \mathrm{~nm}$ emission bands of $\mathrm{Cd} / \mathrm{Ne}$, $\mathrm{Cd} / \mathrm{Ar}$, and $\mathrm{Cd} / \mathrm{Kr}$ are, from the values of the radiative lifetimes measured, 1.26, 1.07, and $1.01 \mathrm{~ns}$, respectively, assigned to the singlet $5 p{ }^{1} P_{1} \rightarrow 5 s{ }^{1} S_{0}$ transition of atomic cadmium which has a gas phase ${ }^{14}$ value of 1.89 ns. This assignment is also given to the additional $262 \mathrm{~nm}$ emission present in the $\mathrm{Cd} / \mathrm{Kr}$ system which has a radiative lifetime of $1.62 \mathrm{~ns}$. Discussion of the origin of the pair of singlet emission bands in the $\mathrm{Cd} / \mathrm{Kr}$ system is presented later.

While the singlet assignment of the UV emissions in the $\mathrm{Cd} / \mathrm{RG}$ systems is straightforward, conclusive transition assignments of the weak emission band at $324 \mathrm{~nm}$ in $\mathrm{Kr}$ and the intense pair at 324 and $329 \mathrm{~nm}$ in the $\mathrm{Cd} / \mathrm{Xe}$ system are, in the absence of exact decay time measurements, not possible. Based on their spectral positions and since these emission bands have lifetimes longer than $1 \mu \mathrm{s}$, these near-UV emission bands must originate from the triplet states of atomic cadmium. The positions of the three $5 s^{1} 5 p^{13} P_{J}$ $-5 s^{2}{ }^{1} S_{0}$ transitions of atomic cadmium in the gas phase are shown in Fig. 5 for comparison with the pair of $\mathrm{Cd} / \mathrm{Xe}$ matrix emissions.

The similar blue shifts of approximately $200 \mathrm{~cm}^{-1}$ on the pair of bands in xenon from the gas phase ${ }^{3} P_{1}-{ }^{1} S_{0}$ and ${ }^{3} P_{0}-{ }^{1} S_{0}$ transitions would, on initial inspection of Fig. 5, suggest that the 324.4 and $329.6 \mathrm{~nm}$ emission bands are due to transitions from the ${ }^{3} P_{1}$ and ${ }^{3} P_{0}$ states, respectively. Indeed, as observed by Crepin and Tramer, ${ }^{3}$ the emission linewidth of the ${ }^{3} P_{0}$ state of $\mathrm{Hg}$ isolated in xenon is narrow (100 $\left.\mathrm{cm}^{-1}\right)$, while that of the ${ }^{3} P_{1}$ state is broad $\left(1200 \mathrm{~cm}^{-1}\right)$. The linewidth difference is not as great as this for the pair of

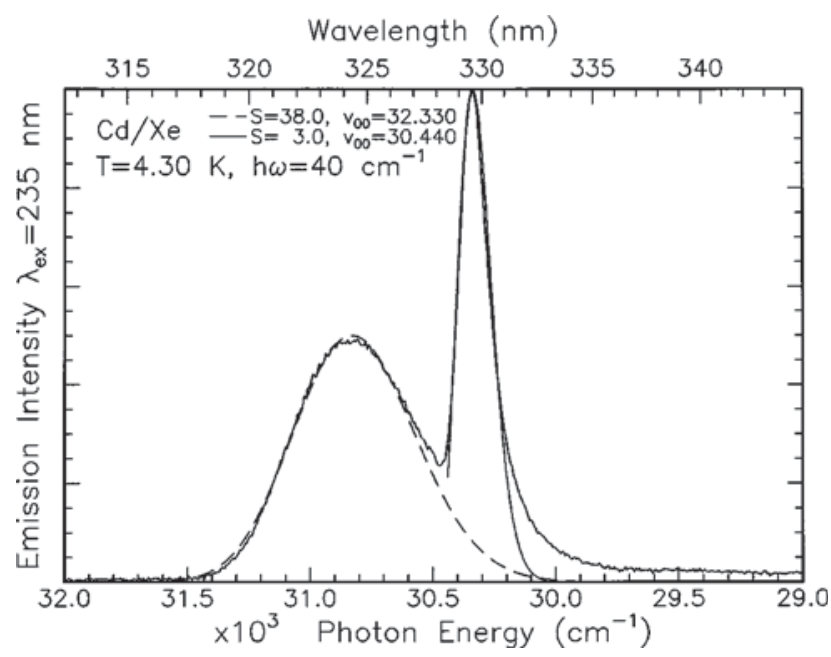

FIG. 8. Fits of the emission bands in the $\mathrm{Cd} / \mathrm{Xe}$ system with the Pekarian line shape function.

emission bands in the Cd/Xe system-the narrow $329.6 \mathrm{~nm}$ band having a FWHM of approximately $150 \mathrm{~cm}^{-1}$ while that of the broad $324 \mathrm{~nm}$ band is $650 \mathrm{~cm}^{-1}$. However, the location and broad linewidth on the $324 \mathrm{~nm}$ would indicate that the ${ }^{3} P_{1}$ assignment is questionable. As direct excitation of these triplet emission bands was not detected, the region of their absorption is not known from measurements. However, from an analysis of the line shapes of the emission bands, estimates of the locations of their absorptions can be made.

Initial attempts were made to fit the pair of emission bands in the $\mathrm{Cd} / \mathrm{Xe}$ system with Gaussian functions. While a satisfactory fit was obtained for the $324 \mathrm{~nm}$ emission, one could not be obtained for the $329 \mathrm{~nm}$ emission, since the profile being red-shaded, as shown in Fig. 8, is asymmetric. Satisfactory fits were, however, obtained for both emission bands using the Pekarian ${ }^{16}$ formula

$$
P(p)=\exp \left[-S \operatorname{coth} \frac{\theta}{2}\right] \frac{\left\{S[1-\exp (-\theta)]^{-1}\right\}^{p}}{p !},
$$

which describes the line shape of a solid state transition having either weak or strong electron-phonon coupling. In this line shape equation, $\theta$ is the ratio of the frequency of the coupling phonon, $\hbar \omega$ and $k T$, where $k$ is Boltzmann's constant and $T$ is temperature in Kelvin units. $S$ is a dimensionless parameter describing the electron-phonon coupling strength while $p$ is the number of phonons coupling. The product of $p$ and the phonon frequency $\hbar \omega$ gives the frequency spectrum $\nu$, while the frequency value at $p=0$ is the location of the zero phonon line, referred to as the electronic band origin, $\nu_{0,0}$ in molecular spectroscopy. In the fits done on the emission bands, the phonon frequency was chosen as $\hbar \omega=40 \mathrm{~cm}^{-1}$ and the experimental temperature of $4.3 \mathrm{~K}$ was used. Identical values were chosen for the phonon frequencies of the two emission bands since they both terminate on the same electronic ground state. The value itself was chosen in the center of the phonon frequency spectrum of solid Xe. The qualities of the fits are shown in Fig. 8. The $S$ and $\nu_{0,0}$ values resulting from the fitting of the two bands are 


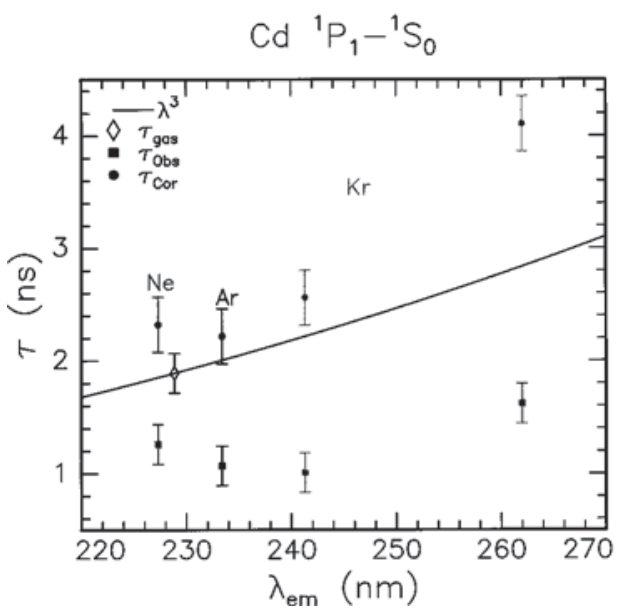

FIG. 9. A comparison of the radiative lifetimes measured for the singlet emission bands in the $\mathrm{Cd} / \mathrm{Ne}, \mathrm{Cd} / \mathrm{Ar}$, and $\mathrm{Zn} / \mathrm{Kr}$ matrix systems and a $\lambda^{3}$ extrapolation of the gas phase lifetime of the $5 p{ }^{1} P_{1}$ state of atomic cadmium. The raw matrix data are shown by the squares, the data corrected for the effective fields of the solid rare gases by the circles.

3 and $30440 \mathrm{~cm}^{-1}$ for the $329.6 \mathrm{~nm}$ band, while values of 38 and $32330 \mathrm{~cm}^{-1}$ were obtained for the $324 \mathrm{~nm}$ band.

The $\nu_{0,0}$ value $\left(30440 \mathrm{~cm}^{-1}\right.$ ) obtained in the fit of the $329.6 \mathrm{~nm}$ emission band strongly supports the ${ }^{3} P_{0}-{ }^{1} S_{0}$ assignment, as this transition occurs at $30114 \mathrm{~cm}^{-1}$ in the gas phase. The observed blue shift in the matrix would indicate the ground $\operatorname{Cd}\left({ }^{1} S_{0}\right)$ state interaction in the matrix is 316 $\mathrm{cm}^{-1}$ stronger than in the excited $\operatorname{Cd}\left({ }^{3} P_{0}\right)$ state. This is consistent with the behavior exhibited in the $\mathrm{Cd} \cdot \mathrm{Ar} 1: 1$ complex, ${ }^{17}$ where binding energies of 97 and $107 \mathrm{~cm}^{-1}$ have been found for the corresponding $\operatorname{Cd}(5 s 5 p){ }^{3} \Pi_{0}-$ and $\mathrm{Cd}\left(5 s^{2}\right) X^{1} \Sigma_{0}$ states of the diatomic. The binding energy of the ${ }^{3} \Pi_{0}-$ state of $\mathrm{Cd} \cdot \mathrm{Xe}$ has not been measured, so the difference in the binding energies is not known for these two states of Cd.Xe. However, if the trends of the other states are consistent, the difference in the binding energy of the ${ }^{3} \Pi_{0}-$ and $X^{1} \Sigma_{0}$ states will be larger in $\mathrm{Cd} \cdot \mathrm{Xe}$ than that of $\mathrm{Cd} \cdot$ Ar. Accordingly, a stronger attractive interaction is expected between the cadmium guest and its xenon host in the ground state than in the excited ${ }^{3} \Pi_{0}-$ state, resulting in a blue shift in the emission relative to the gas phase.

In contrast, the value of $32330 \mathrm{~cm}^{-1}$ obtained for $\nu_{0,0}$ of the $324 \mathrm{~nm}$ band puts the band origin considerably in excess of the ${ }^{3} P_{1}-{ }^{1} S_{0}$ transition at $30656 \mathrm{~cm}^{-1}$ and even slightly above the ${ }^{3} P_{2}-{ }^{1} S_{0}$ transition at $31827 \mathrm{~cm}^{-1}$. It must, however, be remembered that an extrapolation of almost 2000 $\mathrm{cm}^{-1}$ is made from the area at $30800 \mathrm{~cm}^{-1}$, where the 324 $\mathrm{nm}$ emission band is fit with Eq. (1) so that a conclusive assignment to the ${ }^{3} P_{2}-{ }^{1} S_{0}$ transition cannot be made. Measurement of the decay time of this emission band is required to enable a conclusive assignment.

\section{B. Radiative lifetimes}

The decay times listed in Table I for the UV emission bands in the $\mathrm{Cd} / \mathrm{Ne}, \mathrm{Cd} / \mathrm{Ar}$, and $\mathrm{Cd} / \mathrm{Kr}$ systems were found to be independent of temperature and are thereby taken as the radiative lifetimes of the excited $5 p{ }^{1} P_{1}$ state of atomic cad- mium isolated in these rare gas solids. Figure 9 shows a plot of the matrix radiative lifetimes, $\tau_{\text {obs }}$, as a function of their emission wavelengths. The solid line shown in Fig. 9 is an extrapolation ${ }^{18}$ of the $5 p{ }^{1} P_{1}$ excited state lifetime of atomic cadmium, having a gas phase value ${ }^{14}$ of 1.89 ns at 228.86 $\mathrm{nm}$, based on the $\lambda^{3}$ dependence expected. It is clear in Fig. 9 that the observed matrix lifetimes, shown by the squares, are significantly less than the $\lambda^{3}$ extrapolation curve of the gas phase lifetime, indicated by the open diamond.

When the matrix emission lifetimes are corrected for the effective field of the $\mathrm{Ne}$, $\mathrm{Ar}$, and $\mathrm{Kr}$ hosts, the values indicated in Fig. 9 by the filled circles result. Correction of the observed matrix lifetimes $\tau_{\text {obs }}$ is made, ${ }^{19,20}$ with the formula

$$
\tau_{\text {cor }}=\tau_{\text {obs }} n\left[\left(n^{2}+2\right) / 3\right]^{2},
$$

which involves the use of the indices of refraction ${ }^{21}$ of the rare gas hosts, $n$, at the wavelengths where the emissions are observed and at the temperature of the measurements (6.3 $\mathrm{K})$. It is evident in Fig. 9 that the $\mathrm{Cd} / \mathrm{Ar}$ and the $241 \mathrm{~nm}$ $\mathrm{Cd} / \mathrm{Kr}$ bands follow the expected behavior. In contrast, the $\mathrm{Cd} / \mathrm{Ne}$ and the $262 \mathrm{~nm} \mathrm{Cd} / \mathrm{Kr}$ band deviate from the $\lambda^{3}$ curve. The reason for the deviation in the latter cases probably stems from the occupancy of excited state atomic cadmium in nonsubstitutional sites in these solids, something not taken into account in Eq. (2).

\section{Origin of pairs of emission bands in $\mathrm{Cd} / \mathrm{Kr}$}

The existence of the pair of singlet emission bands at 241 and $262 \mathrm{~nm}$ in the $\mathrm{Cd} / \mathrm{Kr}$ system is unique in the spectroscopy of matrix-isolated atomic cadmium but has been observed $^{2}$ for the $\mathrm{Zn} / \mathrm{Ar}$, Zn/Kr, and Zn/Xe matrix systems and analyzed ${ }^{22}$ from a pair potentials approach. It should also be mentioned that a pair of singlet emission bands has been reported for the $\mathrm{Hg} / \mathrm{Ar}$ system following $6 p{ }^{1} P_{1}-6 s{ }^{1} S_{0}$ excitation, but as excitation spectra and precise lifetime measurements of the two bands were not presented in the study of Crepin et al., ${ }^{23}$ conclusive identification cannot be made in this case. The 241/262 nm Cd/Kr emission pair have identical excitation features, and from annealing studies it can be concluded that they are not arising because of multiple site occupancy. Indeed, the pair of $\mathrm{Cd} / \mathrm{Kr}$ emission bands exhibit the same temperature dependence as that described ${ }^{24}$ in detail for the Zn/Ar matrix system, in which the intensity of the higher energy emission band can, as shown in Fig. 4, reversibly be put into the lower energy band by increasing the temperature. Furthermore, measurement of the emission time decay curves indicated that the decay time of the $241 \mathrm{~nm}$ band was getting shorter with increasing temperature, while that of the $262 \mathrm{~nm}$ band remained constant but did exhibit a temperature dependent rise time component. From the time constants extracted from fits of the decay curves in the temperature range $9-20 \mathrm{~K}$ it was observed ${ }^{25}$ that the decay time of the $242 \mathrm{~nm}$ band was the same as the rise time of the 262 $\mathrm{nm}$ band. Kinetics analysis of this behavior indicates ${ }^{24}$ that a single step connects the two emitting levels.

The reason for the existence of two emission minima in $\mathrm{Cd} / \mathrm{Kr}$, while only single minima exist in the $\mathrm{Cd} / \mathrm{Ne}$ and $\mathrm{Cd} / \mathrm{Ar}$ systems, is not immediately evident. However, it could be proposed that favorable size matching of the $\mathrm{Cd}-\mathrm{Kr}$ 
TABLE III. Comparison of the site diameters of the solid rare gases and the equilibrium internuclear separations $r_{e}$ of the Cd.RG diatomics in the ground $X^{1} \Sigma_{0}$ and first excited $C{ }^{1} \Pi_{1}$ electronic states. All the distances are in $\AA$ units, the lattice parameters, $a$, quoted for the solid rare gases are the values at $4 \mathrm{~K}$, given in Ref. 10. The molecular bond lengths are those listed in Ref. 4.

\begin{tabular}{cccccc}
\hline \hline $\mathrm{RG}$ & $a$ & $I_{\mathrm{Oh}}$ site $(\varnothing)$ & Sub.site $(\varnothing)$ & $r_{e} X^{1} \Sigma_{0}$ & $r_{e}{ }^{1} \Pi_{1}$ \\
\hline $\mathrm{Ne}$ & 4.460 & 1.306 & 3.154 & 4.26 & 3.61 \\
$\mathrm{Ar}$ & 5.312 & 1.556 & 3.756 & 4.31 & 3.28 \\
$\mathrm{Kr}$ & 5.644 & 1.653 & 3.991 & 4.33 & 3.17 \\
$\mathrm{Xe}$ & 6.131 & 1.796 & 4.335 & 4.55 & 3.36 \\
\hline \hline
\end{tabular}

bond lengths in the excited $C^{1} \Pi_{1}$ state and the octahedral site size of the larger $\mathrm{Kr}$ lattice might enable excited state occupancy of atomic cadmium in a site not accessible in the lighter rare gases. Thus, as shown in Table III, the $r_{e}$ value of the $C^{1} \Pi_{1}$ state of $\mathrm{Cd} \cdot \mathrm{Kr}$ is $3.17 \AA, 0.35 \AA$ greater than the distance from the center of an octahedral interstitial site to the center of an adjacent substitutional site $2.822 \AA$, $(a / 2)$ but a much better match than in $\mathrm{Ne}$ and $\mathrm{Ar}$, where the differences are 1.38 and $0.62 \AA$, respectively. In none of the other rare gas solids, with the exception of Xe $(0.30 \AA)$, does such a size match exist, but as shown in Fig. 7, a singlet emission is not observed in $\mathrm{Cd} / \mathrm{Xe}$ because of very efficient intersystem crossing. This removes the possibility for the observation of a pair of singlet emission bands in the $\mathrm{Cd} / \mathrm{Xe}$ system. Detailed pair potential calculations such as those presented in the Zn/RG systems, ${ }^{22}$ which are currently underway, are required to identify the origin of the $\mathrm{Cd} / \mathrm{Kr} 241 /$ $262 \mathrm{~nm}$ emission pair.

\section{Photophysical characteristics}

As shown in Fig. 1, the ${ }^{1} P_{1} \leftarrow{ }^{1} S_{0}$ absorption bands of atomic cadmium in solid neon and argon exhibit strong blue shifts $\left(\delta=+1865\right.$ and $\left.+1679 \mathrm{~cm}^{-1}\right)$ from the position of this transition in the gas phase. In $\mathrm{Kr}$ the blue shift is minor

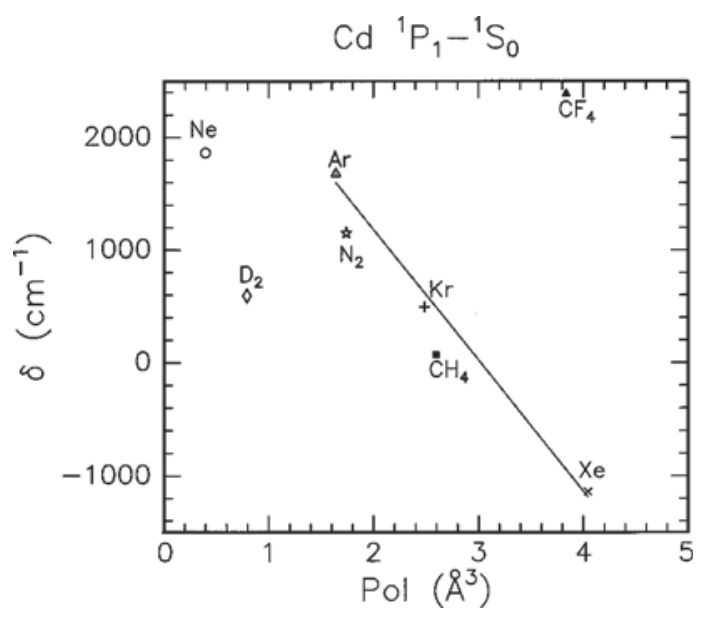

FIG. 10. A plot of the shifts observed for the singlet $5 p{ }^{1} P_{1}-5 s{ }^{1} S_{0}$ absorption of matrix isolated atomic cadmium from the position in the gas phase versus the polarizabilities of the host materials. The line shown is a linear fit of the $\mathrm{Ar}, \mathrm{Kr}$, and Xe data showing the deviation exhibited in the Ne data. Host materials other than the solid rare gases are shown for comparison. The polarizability data used are those listed in Ref. 26.
( $\delta=+496 \mathrm{~cm}^{-1}$ ), while in xenon, a substantial redshift ( $\delta$ $=-1140 \mathrm{~cm}^{-1}$ ) is observed. The shifting of the resonance transition in the Ar, Kr, and Xe systems was observed in the earlier absorption study of Laursen and Cartland ${ }^{8}$ and analyzed on the basis of a linear dependence on the polarizability of the host atom. The straight line shown in Fig. 10 is a linear fit of the observed matrix shifts to the atomic polarizabilities ${ }^{26}$ of $\mathrm{Ar}, \mathrm{Kr}$, and Xe. However, as made evident in Fig. 10, inclusion of the newly recorded $\mathrm{Cd} / \mathrm{Ne}$ data shows a deviation from the linear behavior exhibited in the heavier rare gases, insofar as the blue shift in neon is much smaller than what is predicted by a linear dependence on polarization.

Furthermore, the Stokes shifts on the singlet emission bands are not monotonic and cannot be analyzed with polarizability arguments alone. Thus as indicated in Table I and illustrated graphically in Fig. 6, the Stokes shifts in Ne, Ar, and $\mathrm{Kr}$ (241 nm band) are 1567, 2519, and $2742 \mathrm{~cm}^{-1}$, respectively. Thus the Stokes shifts of the $\mathrm{Cd} / \mathrm{Ar}$ and $\mathrm{Cd} / \mathrm{Kr}$ systems are similar, while that in $\mathrm{Cd} / \mathrm{Ne}$ is substantially smaller and the $262 \mathrm{~nm}$ band in $\mathrm{Cd} / \mathrm{Kr}$ is very large. This behavior indicates that a complete description of the behavior of matrix-isolated atomic cadmium is not possible using macroscopic data. In particular, microscopic details such as the site of isolation and the nature of the atomic states involved in the electronic transitions must be considered to account for the observed behavior.

Data obtained from spectroscopic studies of the diatomic $\mathrm{Cd} \cdot \mathrm{RG}$ van der Waals complexes allow an interpretation of this behavior. The equilibrium internuclear separations in the ground $X^{1} \Sigma_{0}^{+}$states of the Cd.RG diatomics are, as listed in Table III, 4.26, 4.31, 4.33, and $4.55 \AA$ in $\mathrm{Cd} \cdot \mathrm{Ne}$, Cd·Ar, $\mathrm{Cd} \cdot \mathrm{Kr}$, and $\mathrm{Cd} \cdot \mathrm{Xe},{ }^{17}$ respectively, while the substitutional site diameters of neon, argon, krypton, and xenon are 3.154, 3.756, 3.991, and $4.335 \AA$ at $4 \mathrm{~K}^{10}$. A comparison of the equilibrium internuclear separation of diatomic $\mathrm{Cd} \cdot \mathrm{Ne}$ to the substitutional site diameter of solid neon indicates that with a size mismatch of $1.11 \AA$, atomic cadmium cannot be accommodated in a single substitutional site of neon without considerable disruption of the neon lattice. Much more favorable size matches exist in the $\mathrm{Cd} / \mathrm{Kr}$ and $\mathrm{Cd} / \mathrm{Xe}$ systems. The degree of cramped isolation of atomic cadmium in the solid rare gases is reflected in the linear dependence of the extent of shifting on the polarizabilities of the matrix hosts. This behavior suggests that atomic cadmium is trapped in a similar site, probably a single substitutional site, for the rare gas solids $\mathrm{Ar}, \mathrm{Kr}$, and $\mathrm{Xe}$, but in a different one in neon.

The next larger site available in a cubic close packed host solid to accommodate a spherical guest is a tetravacany, that is the removal of a tetrahedron of four adjacent host atoms. Indeed, the much smaller than expected blue shift observed in the $\mathrm{Cd} / \mathrm{Ne}$ absorption spectrum is consistent with cadmium occupying a large site in the neon lattice such as that offered by a tetravacancy.

\section{E. Intersystem crossing}

As illustrated in Figs. 6 and 7, the emission spectra of the $\mathrm{Cd} / \mathrm{RG}$ systems reflect the very different efficiencies of 
intersystem crossing of matrix-isolated atomic cadmium. A pronounced trend is identifiable in that the lighter rare gases $\mathrm{Ne}$ and Ar exhibit no spin triplet emission, while a weak triplet is observed in $\mathrm{Kr}$ and no singlet is observed in $\mathrm{Cd} / \mathrm{Xe}$. This difference in the efficiency of spin singlet to triplet intersystem crossing in the Cd/RG matrix systems correlates with the spectroscopic ${ }^{5}$ and pump-probe ${ }^{6}$ studies done by Breckenridge and co-workers on the diatomic Cd·RG van der Waals species in cold supersonic expansions. In this work strong fluorescence is found for the $C^{1} \Pi_{1}$ state of the $\mathrm{Cd} \cdot \mathrm{Ne}, \mathrm{Cd} \cdot \mathrm{Ar}$, and $\mathrm{Cd} \cdot \mathrm{Kr}$ complexes, while fluorescence could not be detected for this state in Cd.Xe. Analysis of the $C^{1} \Pi_{1}$ state in $\mathrm{Cd} \cdot$ Xe was achieved in a pump-probe study ${ }^{6}$ whereby the atomic Cd $6 s^{3} S_{1}-5 p{ }^{3} P_{2}$ transition was used as a probe for the production of Cd $5 p^{3} P_{2}$ following excitation of the molecular $C^{1} \Pi_{1}$ state. The very efficient production of the $\mathrm{Cd} 5 p^{3} \mathrm{P}_{2}$ state was identified as arising from spin-orbit induced predissociation of the bound $C^{1} \Pi_{1}$ state due to a crossing with the repulsive ${ }^{3} \Sigma_{1}$ state which correlates with the $5 p^{3} P_{2}$ state of Cd.

More recently, a theoretical analysis based on the molecular $C^{1} \Pi_{1} /{ }^{3} \Sigma_{1}$ predissociation mechanism has been presented $^{27}$ which predicts the efficiency of the ISC of atomic zinc isolated in the rare gas solids. The results of this recent work indicate that the external heavy atom effect is not responsible for the enhancement of the ISC in the heavier rare gas hosts. Rather it is determined by the occurrence of spin singlet and spin triplet surface crossings at lower energies in the heavier hosts than in the lighter rare gases. While this analysis has not yet been carried out on the Cd/RG matrix systems, it would seem likely that the same behavior will be found as in the $\mathrm{Zn} / \mathrm{RG}$ systems.

\section{CONCLUSIONS}

Based on their spectral locations and radiative lifetimes, the emission bands present in the $\mathrm{UV}$ for $\mathrm{Cd} / \mathrm{Ne}, \mathrm{Cd} / \mathrm{Ar}$, and $\mathrm{Cd} / \mathrm{Kr}$ are assigned to the $5 p^{3} P_{1}-5 s{ }^{1} S_{0}$ transition of atomic cadmium. In $\mathrm{Cd} / \mathrm{Xe}$ no singlet emission exists but a pair of long-lived bands occur in the near-UV. The narrower band centered at $324.4 \mathrm{~nm}$ is tentatively assigned to the $5 p{ }^{3} P_{0}-5 s{ }^{1} S_{0}$ transition based on line shape analysis. Precise decay time measurements of the near-UV pair are required to conclusively identify the spin-orbit levels involved in these transitions. The efficiency of spin triplet to singlet intersystem crossing in the $\mathrm{Cd} / \mathrm{RG}$ systems is similar to that previously observed in the $\mathrm{Zn} / \mathrm{RG}$ series. In contrast, in the Zn/RG systems, the presence of emission from the $5 p{ }^{3} P_{0}$ level in $\mathrm{Cd} / \mathrm{Xe}$ is more similar to the $\mathrm{Hg} / \mathrm{RG}$ systemsbehavior consistent with the larger spin-orbit splitting in cadmium compared with zinc. The matrix and Stokes shifts recorded on the Cd singlet bands in the full range of the solid rare gases used in this study do not exhibit a linear dependence on host polarizability. This behavior indicates that microscopic details such as the site of isolation and the nature of the atomic states involved in the electronic transitions must be considered to account for the observed shifts. Extension of the theoretical pair potentials model developed for the $\mathrm{Zn} / \mathrm{RG}$ matrix system is currently underway for the $\mathrm{Cd} / \mathrm{RG}$ systems and will be presented in a future publication.

\section{ACKNOWLEDGMENTS}

We would like to acknowledge Dr. Peter Gürtler and Sven Petersen for their technical assistance during the course of this work. This research was funded in part by the European Union, TMR 1996-1998, “'Access to Large Scale Facilities”' ERBFMGECT 950059 Programme and by the Irish Government Forbairt Basic Science research scheme to whom B.H. also gratefully acknowledges receipt of a Ph.D studentship. In addition, we gratefully acknowledge Professor Bill Breckenridge for bringing details of the gas phase LIF spectroscopy on the Cd.RG van der Waals species to our attention.

${ }^{1}$ J. G. McCaffrey and G. A. Ozin, J. Chem. Phys. 101, 10354 (1994).

${ }^{2}$ V. A. Bracken, P. Gürtler, and J. G. McCaffrey, J. Chem. Phys. 107, 5290 (1997).

${ }^{3}$ C. Crepin and A. Tramer, J. Chem. Phys. 97, 4772 (1992).

${ }^{4}$ W. H. Breckenridge, C. Jouvet, and B. Soep, in Advances in Metal and Semiconductor Clusters, edited by M. A. Duncan (JAI, Greenwich, 1995), Vol. III.

${ }^{5}$ D. J. Funk, A. Kvaran, and W. H. Breckenridge, J. Chem. Phys. 90, 2915 (1989).

${ }^{6}$ D. J. Funk and W. H. Breckenridge, J. Chem. Phys. 90, 2927 (1989).

${ }^{7}$ W. W. Duley, Proc. Phys. Soc. London 91, 976 (1967); Nature (London) 210, 264 (1966).

${ }^{8}$ S. Laursen and H. Cartland, J. Chem. Phys. 95, 4751 (1991).

${ }^{9}$ C. E. Moore, Atomic Energy Levels, National Bureau of Standards Circular Number 467 (U.S. Government Printing Office, Washington D.C., 1957), Vol. 1, p. 125.

${ }^{10}$ G. L. Pollack, Rev. Mod. Phys. 36, 748 (1964).

${ }^{11}$ D. V. O’Connor and D. Phillips, Time Correlated Single Photon Counting (Academic, London, 1984).

${ }^{12}$ G. Zimmerer, Nucl. Instrum. Methods Phys. Res. A 308, 178 (1991).

${ }^{13}$ ZFIT program, Nonlinear Least Squares Analysis of Fluorescence Decay Data, M. Rehorek, H. Otto, W. Rettig, and A. Klock, and modified by P. Gürtler and M. Joppien, last update August 1995.

${ }^{14}$ J. R. Fuhr and W. L. Wiese, Handbook of Chemistry and Physics, edited by D. R. Lide, 73rd ed. (CRC, Boca Raton, 1991-1993).

${ }^{15}$ J. Rose, D. Smith, B. E. Williamson, P. N. Schatz, and M. C. M. O’Brien, J. Phys. Chem. 90, 2608 (1986).

${ }^{16}$ The $S$ and $\hbar \omega$ terms appearing in the Pekarian line shape formula [Eq. (1)] are identical to the coupling strength and the frequency of the effective coupling phonon used in Huang-Rhys (HR) theory of electron-phonon coupling [K. Huang and A. Rhys, Rhys, Proc. R. Soc. London, Ser. A 204A, 406 (1950)]. In HR theory the line shape function is $W p=\exp$ $(-S(1+r) /(1-r)) r^{-p / 2} \operatorname{Ip}\left(2 S\left(r^{1 / 2}\right) /(1-r)\right)$, in which $r=\exp (-\theta)$ and $p$ is the phonon number. Equation (1) is the first term in the expansion of the $W p$ function, and at low temperatures it approximates the latter very well. The line shape generated with the $W p$ function, using the $S$ and $\hbar \omega$ terms extracted for the $329 \mathrm{~nm}$ emission band recorded at $4.3 \mathrm{~K}$ in the $\mathrm{Cd} / \mathrm{Xe}$ system, was identical to that generated with Eq. (1). The advantage of using Eq. (1) over the $W p$ function is that it avoids use of the modified Bessel function $\operatorname{Ip}(x)$ appearing in the $W p$ expression, which makes fitting to this formula difficult and unreliable. For a more detailed discussion of these functions, see C. W. Struck and W. H. Fonger, Understanding Luminescence Spectra and Efficiency Using Wp and Related Functions (Springer-Verlag, Berlin, 1991), Chap. 4.

${ }^{17}$ R. R. Bennett and W. H. Breckenridge, J. Chem. Phys. 96, 882 (1992).

${ }^{18}$ The $\lambda^{3}$ extrapolation of the gas phase radiative lifetime of a level $m$ is made on the basis of the expression for the Einstein $A$ coefficient for the emission $A_{m n}=\left(64 \pi^{4} / 3 h \lambda^{3}\right) \mu_{m n}^{2}=1 / \tau_{m}$.

${ }^{19}$ R. L. Fulton, J. Chem. Phys. 61, 4141 (1974).

${ }^{20}$ T. Shibuya, J. Chem. Phys. 78, 5175 (1983).

${ }^{21}$ The index of refraction of $\mathrm{Ar}$ at $233 \mathrm{~nm}$ is 1.32 at $6 \mathrm{~K}$. Those of $\mathrm{Kr}$ at 241 and $262 \mathrm{~nm}$ are 1.428 and 1.418, respectively (P. Gürtler, unpublished results, 1996).

${ }^{22}$ P. N. Kerins and J. G. McCaffrey, J. Chem. Phys. 106, 7885 (1997).

${ }^{23}$ C. Crepin, M. Chergui, T. Herbert, L. Koenig, P. Martin, and A. Tramer, J. Phys. Chem. 98, 3280 (1994).

${ }^{24}$ V. A. Bracken, P. N. Kerins, P. Gürtler, and J. G. McCaffrey, J. Chem. Phys. 107, 5300 (1997). 
${ }^{25}$ From an Arrhenius plot of the nonradiative rate constants extracted from the decay time of the $242 \mathrm{~nm}$ band and the rise time of the $262 \mathrm{~nm}$ band, a barrier height of $16 \mathrm{~cm}^{-1}$ intervenes between the two minima. B. Healy and J. G. McCaffrey, unpublished results, 1998.
${ }^{26}$ T. M. Miller, Handbook of Chemistry and Physics, edited by D. R. Lide, 73rd ed. (CRC, Boca Raton, 1991-1993).

${ }^{27}$ W. H. Breckenridge, M. D. Morse, and J. G. McCaffrey, J. Chem. Phys. 109, 3137 (1998). 